\title{
Um teatro feito da matéria dos sonhos: Os gigantes da montanha e o Grupo Galpão
}

\section{A theater made of the dreams matter: The giants of the mountain and the Galpão Group}

Martha de Mello Ribeiro ${ }^{1}$ 


\section{Resumo}

A questão que acompanhou Pirandello em suas reflexões sobre o teatro, refletida em sua composição dramatúrgica, foi a dolorosa certeza da impossibilidade da representação cênica. No caso do autor italiano, o irrepresentável encontra-se na impossibilidade do ator em representar um outro ser. Estamos diante de um modo de pensar o teatro que revoga a representação de dentro, apontando como impossível o ato de representar um papel; seu projeto maior foi nos fazer ver o impensável, engendrando em sua dramaturgia personagens que se auto-representam. Tal pensamento se materializa de forma indiscutível em "Os Gigantes da Montanha" (1936), que na montagem do Grupo Galpão encontra os meios ideais para a composição dos sonhos.

Palavras-chave: Luigi Pirandello; Os Gigantes da Montanha; Experiência; Grupo Galpão.

\section{Abstract}

The question that followed Pirandello in his reflections about theater, reflected in his dramaturgical composition, it was the painful sure of the impossibility of scenic representation. In the case of the italian author, the unactable is in the impossibility of the actor represent another being. We are above a way of thinking about theater that repeals representation from within, showing that is impossible the act of play a role, his biggest project was to make us see the unthinkable, engendering in his dramaturgy, characters that represent themselves. Such thought materializes in a unquestionable way in "Os Gigantes da Montanha" (1936) that in its presentation by Grupo Galpão finds the ideal mean for the composition of the dreams.

Keywords: Luigi Pirandello; Os Gigantes da Montanha; Experience; Grupo Galpão.

ISSN: 1414.5731

E-ISSN: 2358.6958

${ }^{1}$ Diretora teatral e Professora Dra. Adjunta do Departamento de Arte e do Programa de Pós-Graduação em Estudos Contemporâneos das Artes da Universidade Federal Fluminense (UFF), Rio de Janeiro, RJ, Brasil. melloribeiro.uff@gmail.com 
Ele, Hamlet, estranho a todos os lugares onde aponta...

(Stéphane Mallarmé)

\section{Qual é o poder do sonho?}

Poderíamos perguntar ao autor italiano Luigi Pirandello (1867-1936), que em sua dolorosa certeza sobre o impoder da representação engendra "Os gigantes da montanha" (1936), obra deixada incompleta, originalmente chamada, não por acaso, "Os fantasmas". Em vez de personagens, a obra poética do dramaturgo insinua aparições, fantasmas, que numa certa vila, chamada La Scalogna, comandada pelo mago Cotrone, questionam - a nós espectadores e aos atores da companhia teatral de Ilse -, a possibilidade do teatro representativo dar a ver a arte ou a poesia, preso como está num sistema de regulagem entre o ver e o dizer. Uma inquietante incorporalidade nos desafia a pensar o "mito da arte", conforme Pirandello conceituou a peça, ou, como iremos desenvolver aqui, a questão do irrepresentável, isto é, a impossibilidade do teatro expressar-se em sua própria língua: o dramático. O que se vislumbra mais uma vez em Pirandello (e pela última vez antes de sua morte) é o confronto entre essas virtualidades, chamadas os Scalognati, e a excessiva carnalidade dos atores da companhia, que insistem em representar um texto poético, provocando, como dirá Pirandello, seu próprio desaparecimento. Confirmando a não utilidade do teatro de poesia num mundo habitado por gigantes.

Em nosso entendimento, a questão que acompanhou Pirandello em suas reflexões sobre o teatro, refletida em sua composição dramatúrgica, foi a dolorosa certeza da impossibilidade da representação em lidar com certos temas, como o incesto ou com o phatos, os excessos de qualquer natureza. No caso do autor italiano, o irrepresentável encontra-se na impossibilidade do ator em representar um outro ser a partir do modelo dramático. Já que toda representação (o sistema mimético) significa uma regulagem da visão, o ator acaba procedendo por escolhas em torno do que é possível e necessário, deixando de fora justamente o que interessava ao dramaturgo italiano: o irrepresentável, as sombras, as idiossincrasias, os excessos, etc. Tal acontecimento, a representação de personagens por um ator devotado a construir um personagem codificado, facilmente reconhecível pelo público, engendraria uma espécie de autoanulação de ambos os polos, esvaziando a real experiência da arte - que deveria estar desobrigada de qualquer regulagem, permitindo o fluir livre dos afetos. Essa impossibilidade aponta uma impotência, ou um "impoder" do teatro regido pelo regime representativo, assim definido por Rancière (2009, p.31):

Ele se desenvolve em formas de normatividade que definem as condições segundo as quais as imitações podem ser reconhecidas como pertencendo propriamente a uma arte e apreciadas, nos limites desta arte, como boas ou ruins, adequadas, ou inadequadas.

Porém, a teoria rancieriana é muito posterior ao dramaturgo, e Pirandello não era um teórico, ou um filósofo, ipsis litteris, nunca chegou a engendrar uma teoria sobre a representação. Mas, como um poeta que era, usou como estratagema a ficção para se fazer entender. O escritor aponta como "solução" para se preservar a vida da poesia dramática a autorrepresentação da obra, que se faria não com os atores, mas 
com os próprios personagens: fantasmas, que por algum "milagre" se materializariam em cena, com corpo e voz.

ILSE: E esta vila, de quem é?

COTRONE: Nossa e de ninguém. Dos Espíritos.

ILSE: Como assim, dos Espíritos?

COTRONE: Exato. Esta vila tem a fama de ser habitada por Espíritos. E por isso, há muito tempo atrás, foi abandonada por seus antigos donos que de tão apavorados fugiram, inclusive da ilha.

ILSE: e vocês não acreditam nos Espíritos...

COTRONE: Como não? Nós os criamos!

ILSE: ah, vocês é que os criam...

COTRONE: Perdoe-me Condessa, mas eu não esperava que justamente a senhora me falasse deste jeito. Como nós, a senhora também deve acreditar neles. Vocês, atores, oferecem o corpo aos fantasmas para que eles vivam - e eles vivem! Nós, ao contrário, fazemos dos nossos corpos, os fantasmas. E da mesma forma os fazemos viver. Os fantasmas... não há nenhuma necessidade de procurá-los muito longe. Basta fazê-los sair de nós mesmos (Pirandello, 2007, p.880).

Solução fantástica que não nos ajuda a avançar em relação ao pensamento sobre a representação, mas aponta para uma insatisfação do autor em relação ao regime representativo de forma tão aguda, que nos permite abrir sua obra para novas possibilidades no campo estético, aproximando-o das mais recentes teorias sobre a arte. Fazer do próprio corpo um fantasma é muito mais do que "emprestar" o corpo ao personagem, como indicado aos atores da estética naturalista. Significa tornar esse corpo, em certa medida, irrepresentável. Se entendermos juntos a Rancière que o irrepresentável só existe precisamente no sistema representativo, justamente por exceder a regulagem das relações entre o ver, o fazer e o dizer presente na conformação da obra verossímil, a ideia de fantasmas que "agem por si só", no lugar dos atores, sem dúvida não se enquadra nas regras do sistema representativo.

Você verá que coisa é I giganti della montagna! É completo, é a orgia da fantasia! A leveza de uma nuvem sobre a profundidade dos abismos. Risos vigorosos explodem entre as lágrimas, como trovões entre as tempestades. É tudo suspenso, aéreo, vibrante, elétrico. Não se pode comparar com nada do que eu fiz até agora. Você verá, estou tocando o ápice! (Pirandello, 1995, p.648).

Reino da fantasia, da arte e da poesia, "Os gigantes da montanha" foi concebido por Pirandello para ser sua obra conclusiva, uma espécie de último adeus ao teatro; como de fato terminou acontecendo. A peça, parafraseando as palavras usadas pelo autor em 1929, se trata da tragédia de uma atriz que deseja continuar a dar vida à obra teatral de um jovem poeta morto, idealmente amado por ela. Porém, todas as tentativas da atriz para fazer com que a obra do poeta seja conhecida e admirada pela sua beleza e novidade, terminam sempre infrutíferas. Mas, quanto mais se multiplicam os fracassos, mais a intérprete se aferra na sua defesa. Numa vida errante, sacrificando sua vida e toda sua riqueza por este ideal, Ilse arrasta consigo uma pequena companhia de atores incapazes, miseráveis e humildes. Em sua peregrinação, a atriz, chamada Condessa, e sua companhia de fracassados chegam à vila, onde vive uma espécie de genius loci (Cotrone), que tentará salvar a companhia de atores e sua primeira atriz da catástrofe inevitável: a destruição de seus corpos pelos gigantes que 
habitam a montanha.

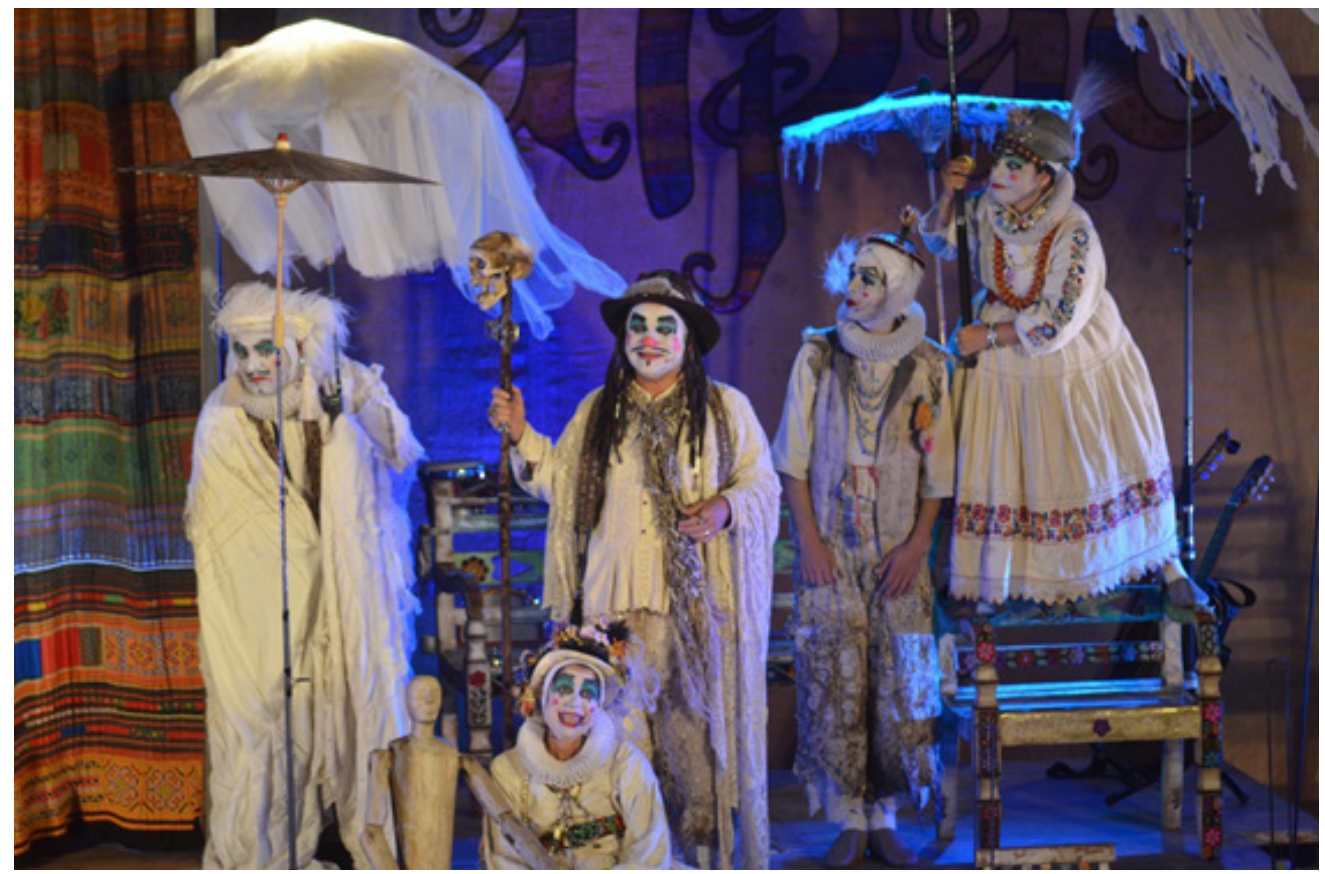

Os Gigantes da Montanha. Grupo Galpão/Direção e concepção: Gabriel Villela. Foto Ricardo Gama

Esse pequeno resumo descritivo da peça demonstra que Pirandello não rompe em definitivo com o sistema representativo, ou melhor, com a ideia de fábula. Há claramente uma história pregressa que informa aos leitores quem são os personagens da companhia da Condessa. Mas interessante notar é que não há nenhuma referência aos personagens que habitam a vila, os Scalognati. Envolvidos por uma aura mágica, esses personagens-fantasma são apontados por Cotrone como a própria criação. E como seria possível definir a criação? A ideia de criação toca o limite da língua, não se deixa operacionar, é um ponto cego, um mistério. O que estamos querendo dizer é que Pirandello realiza esses personagens da vila em outro registro, buscando uma outra língua, que ainda não somos capazes (junto com llse) de imaginar, pois escapa, excede ao nosso pensamento. Ao confrontar a companhia teatral de llse com os Scalognati, o dramaturgo nos desafia a viver uma experiência não representável, rebelde: uma cena que repousa justamente na impossibilidade de se expressar em sua própria língua, isto é, a partir dos códigos inerentes ao drama, à representação.

A ação proposta por Cotrone é imediata, "[...] basta imaginar e imediatamente as imagens ganham vida!" (Pirandello, 2013, p. 101). A cena, povoada destes personagens-fantasma, ultrapassa o teatro em seu paradigma dramático. Mas de que se trata esse ultrapassamento? Pirandello não vai propor uma nova norma para a representação, ou um novo modo para o ator representar um personagem; tal feito só iria substituir um método por outro, e permaneceríamos no sistema representativo, de produção objetivada. O que o dramaturgo convoca na famosa cena das aparições, na terceira parte da peça ${ }^{2}$, é algo da natureza do acontecimento, isto é, algo que nos afeta, sem darmos conta ou mesmo desejarmos, mas que temos vontade de falar: nossa experiência; que conforme entende o filósofo Jorge Larrosa: "é o que nos pas- 
sa, o que nos acontece, o que nos toca" (2014, p.18). E como dirá Cotrone: "A vila é assim mesmo. Todas as noites fica em estado de música e sonho" (Ibid, p. 96). As aparições na vila, testemunhada com espanto e estranheza pelos atores, não devem ser entendidas enquanto delírio, fantasia ou ilusão, mas como uma tentativa de despertar-nos para a experiência, subvertendo o sentido das coisas, interrompendo toda representação, enfim, alargando nosso pensamento para além do que ele pode dominar.

A experiência é algo que (nos) acontece e que às vezes treme, ou vibra, algo que noz faz pensar, algo que nos faz sofrer ou gozar, algo que luta pela expressão, e que às vezes, algumas vezes, quando cai em mão de alguém capaz de dar forma a este tremor, então, somente então, se converte em canto. E esse canto atravessa o tempo e o espaço. E ressoa em outras experiências e em outros tremores e em outros cantos (Larrosa, 2014, p.10).

Os gigantes da montanha não é apenas a última peça escrita por Pirandello, o texto deixado em aberto pelo autor se traduz como o canto de experiência de Pirandello sobre o teatro. Um canto apaixonado e sofrido da sua experiência no teatro. Esse canto atravessou o tempo e chegou até o Grupo Galpão, na montagem dirigida por Gabriel Villela para os 30 anos da companhia mineira. Um outro canto de experiência sobre o teatro, um outro tremor convertido em canto, ressoa nessa linda montagem que se debruça sobre o sonho de se fazer teatro, de se cantar o teatro, de viver a experiência selvagem desse sonho que não se deixa moldar ou aplacar.

Em entrevista concedida a mim em 11 de outubro de 2013 durante o evento "Encontro com o Grupo Galpão", que organizei na Universidade Federal Fluminense, Eduardo Moreira, um dos fundadores do grupo, e a atriz Inês Peixoto, integrante há vinte e três anos da companhia, assim falam de sua experiência com o teatro e o texto pirandelliano:

Autor: Queria pegar esse gancho, que eu acho fantástico, em relação ao Os gigantes da montanha, [...] que é, digamos, o olhar desse autor para toda a trajetória dele no teatro; e de como o teatro influenciou os seus últimos dez anos de vida, que foram aqueles mais importantes, pois ele sempre disse que não vivia, e ele passa a viver a partir do momento que conhece a fundo os porões, os interiores do teatro, as dificuldades e ao mesmo tempo as generosidades, de tudo de humano que existe nesse caldeirão que é fazer teatro.

Eduardo: [...] o que eu acho muito lindo do Pirandello como artista, um artista realmente extraordinário, é que ele mesmo consagrado - conseguiu o prêmio Nobel de literatura em 1934 - continua se perguntando sobre qual a possibilidade, qual a natureza do teatro dele, qual a saída do teatro. [...] Existe uma pergunta muito pungente no "Os gigantes da montanha": qual é a possibilidade do teatro no mundo dele. Eu acho que essa pergunta se tornou cada vez mais radical e urgente ao longo dos anos, eu acho que na nossa época a gente está se perguntando, o que o teatro tem pra dizer num mundo onde as pessoas tem acesso a tudo, não precisam

${ }^{2}$ Cf Luigi Pirandello, Os gigantes da montanha. Tradução Maria de Lourdes

Rabetti. Rio de Janeiro: 7Letras, 2013, p. 75-109. 
sair de casa, num mundo extremamente dividido e individualizado, onde o espaço público está completamente esvaziado, num sentido de que as pessoas tem medo de se encontrar, de ir para as ruas e ver um espetáculo de teatro [...] eu acho que em 1936 quando Pirandello morre ele tá angustiado e ele propõe ali com "Os gigantes", [...] que a saída para o teatro é um mergulho radical na poesia e no sonho.

Inês: $\mathrm{E}$, esse delírio que parece que a peça é um sonho, é um delírio assim do Pirandello, um delírio que ele construiu durante oito anos, é como um sonho no qual você lembra de partes, a gente acaba conseguindo que as pessoas tenham essa sensação, você não está vendo a representação de um sonho, a plateia às vezes nos dá um retorno de que elas se sentem dentro de um sonho assim, é sensorial, sabe?! Não importa mais entender, seguir uma história direitinho assim, às vezes a peça, a gente tem esse retorno, de conseguir pegar a plateia e levar para um delírio, sabe?! Para uma experiência, isso é interessante também.

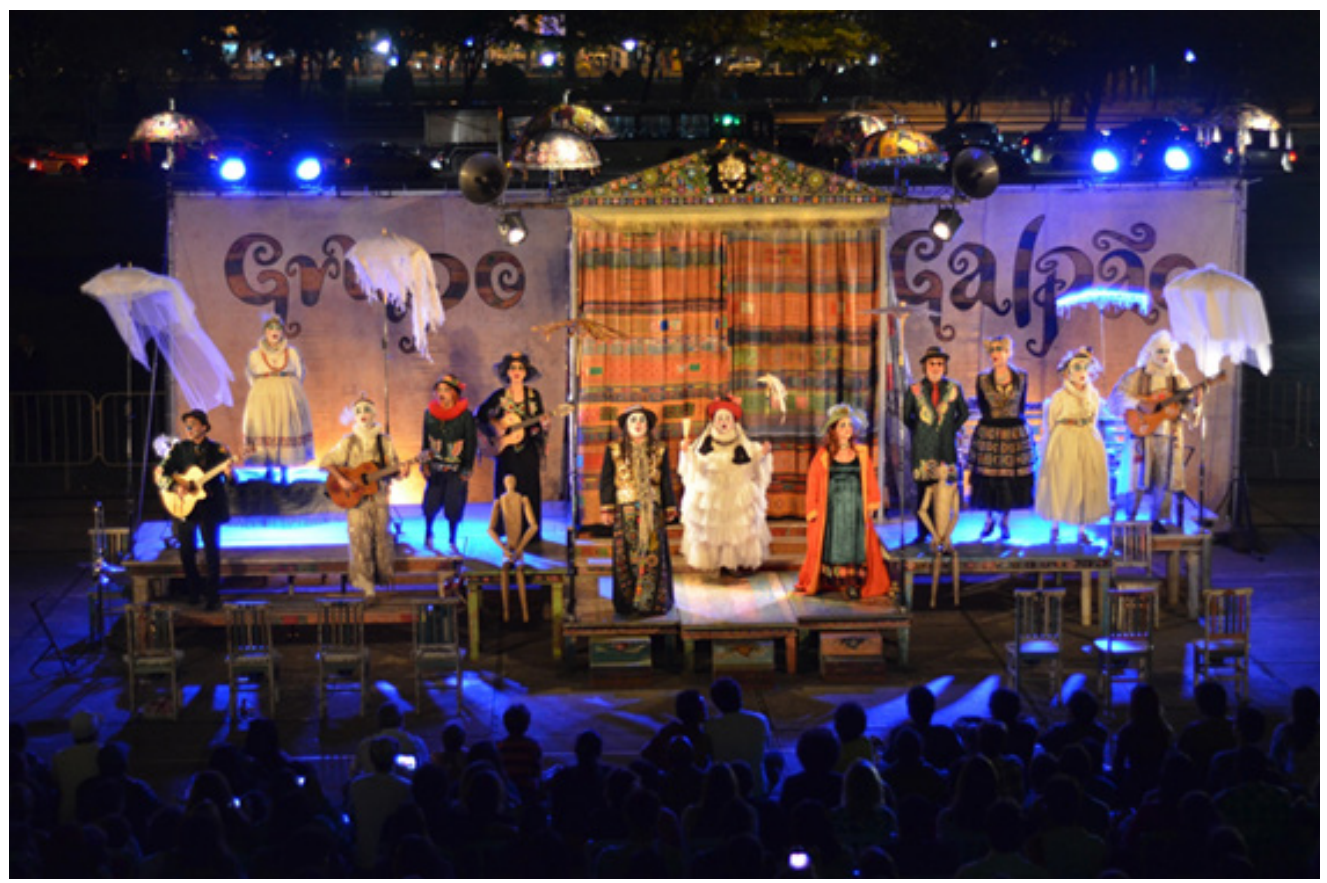

Os Gigantes da Montanha. Grupo Galpão/Direção e concepção: Gabriel Villela. Foto Ricardo Gama.

O sujeito da informação é o avesso do sujeito da experiência. A montagem de "Os gigantes da montanha" pelo grupo Galpão foi concebida para um teatro de rua, lugar de perigos e atravessamentos, lugar para ressoar cantos de experiências.

A palavra experiência, que não é um conceito, mas o que nos acontece e que nos faz tremer a carne, que não é possível definir, mas apenas cantar, é tudo que nos acomete, que nos empossa. Pirandello se investia de teatro, e esse canto ressoa na montagem do Grupo Galpão, nas palavras de Inês e Eduardo, na linguagem do teatro de rua. Um lugar de passagem, de troca, onde só fica quem é de fato tocado. Esse canto de experiência toca os limites de nossa língua, pois não é possível encontrar uma definição, trata-se de vertigem. Larrosa em seu livro "Tremores" nos adverte sobre o que a experiência não é. E a primeira coisa a fazer é separá-la da informação: "uma sociedade constituída sob o signo da informação é uma sociedade na qual a experiência é impossível" (2014, p.20). Evocamos aqui Walter Benjamim (1936) na afirmação de que o verdadeiro declínio da experiência veio com a proliferação da informação, que "aspira a uma verificação imediata". A informação é avessa à con- 
templação, ao surpreendente, ela é instantânea, vem com uma explicação plausível, anterior à experiência. Já o canto de experiência é um canto rebelde, avesso à falsa experiência, à experiência autoritária. $\mathrm{O}$ sujeito da experiência é um rebelde, um outsider.

E o palco do sujeito da experiência é a rua. Lugar onde o sujeito encontra-se ex -posto, vulnerável e em risco: "Por isso é incapaz da experiência aquele a quem nada Ihe passa, a quem nada the acontece, a quem nada lhe sucede, a quem nada o toca, nada the chega, nada o afeta, a quem nada o ameaça" (Larrosa, 2014, p.26). O sujeito da informação é o avesso do sujeito da experiência. A montagem de "Os gigantes da montanha" pelo grupo Galpão foi concebida para um teatro de rua, lugar de perigos e atravessamentos, lugar para ressoar cantos de experiências. O extraordinário, o sonho e o miraculoso escapam a qualquer determinação, e a rua tradicionalmente é o lugar do artista outsider, do artesão, do prestidigitador. Se pensarmos no sonho como um desvio da realidade e consequentemente da informação, começamos a perceber que o sonho é um outro tipo de saber, diferente do científico, um saber que convoca um outro tempo, um tempo do olhar. E "Os gigantes" do Galpão conseguiu provocar em nós, espectadores, esse tempo do olhar. Um tempo que rumina lento, onde saboreamos nossa própria disponibilidade de ser acometido.

Diante do teatro de poesia de Pirandello que ressoa, vibra, no canto de experiência do Galpão, somos acometidos por uma "passividade anterior à oposição entre ativo e passivo, de uma passividade feita de paixão", conforme nos diz Larrosa (loc. cit). Ficamos disponíveis aos pequenos detalhes, aos silêncios, num tempo do olhar que não costumamos mais ter hoje em dia por falta de tempo ou por medo. Se tudo se passa muito rápido, muito frenético, acaba que nada nos ocorre. E o Grupo Galpão é um dos poucos grupos hoje em dia que de fato enfrenta o risco de fazer do teatro um canto de experiência. Na linguagem popular, no teatro de rua, proposto pelo grupo e pelo diretor Gabriel Villela, mergulhamos na poesia pirandelliana, e sentindo o tremor de nossa carne, junto com Ilse, enfrentamos os gigantes. E aqui citamos Benjamim: "o narrador [ou o sujeito da experiência] é o homem que poderia deixar a luz tênue de sua narração consumir completamente a mecha de sua vida" (1985, p.221). E não é isso que os artistas apaixonados fazem?

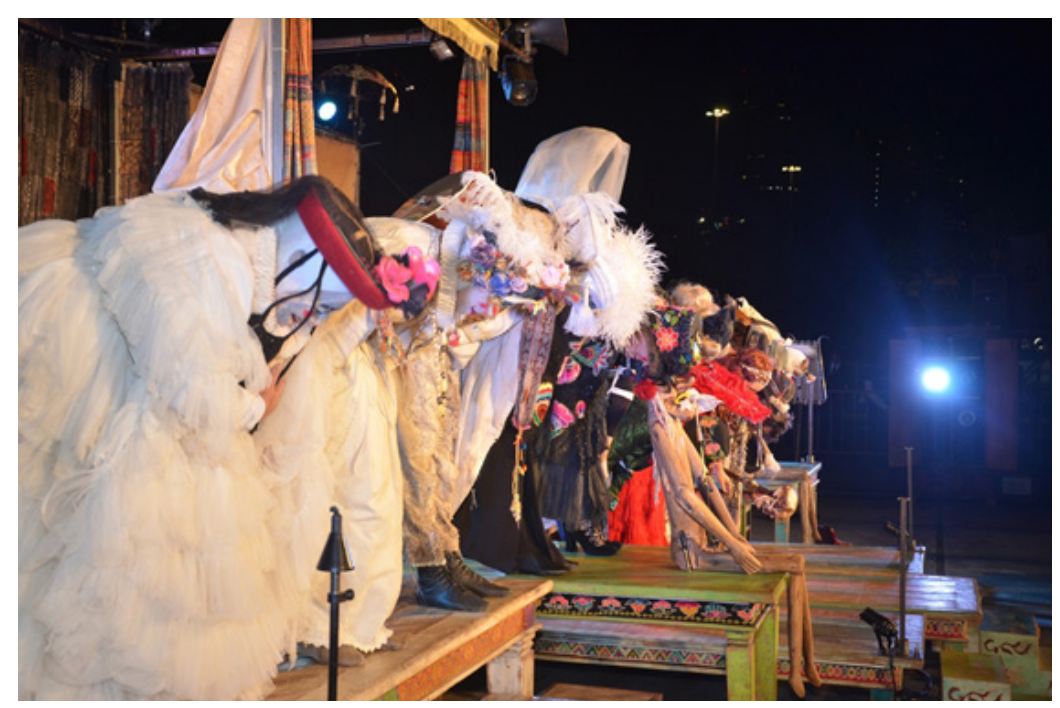

Os Gigantes da Montanha. Grupo Galpão/Direção e concepção: Gabriel Villela. Foto Ricardo Gama. 
Nas entrevistas que concedeu entre 1928 e 1930, Pirandello previa um final trágico para Ilse e todos os seus atores, mortos barbaramente pelos gigantes. "La favola del figlio cambiato"3 seria o divertimento oferecido pelos gigantes aos seus servos por ocasião de uma festa de casamento. Os servos, já bêbados e não compreendendo absolutamente nada, exigem outro espetáculo, explodindo por fim um pandemônio. Ilse é agredida e assassinada violentamente, Spizzi e Diamante, ao tentar defendê-la, também são mortos. O IV momento (ou terceiro ato) nunca foi escrito. Pirandello, antes de morrer, narrou sua visão ao seu filho Stefano. A peça deixada incompleta aponta a dificuldade do autor em resolver o conflito final entre a arte de Ilse e os embrutecidos gigantes (que conhecendo as cartas de Pirandello para Marta Abba, podemos dizer que se trata de uma referência aos empresários, público e críticos da época4). O momento do combate definitivo foi permanentemente adiado demonstrando a dificuldade do autor em achar uma solução em face à inevitável tensão/colisão entre o teatro, concebido como arte para iniciados, e as exigências concretas do fazer teatral. "Os gigantes da montanha", em sua incompletude, é a expressão deste conflito e também o confessar da impossibilidade do poeta em superá-lo. Diz Cotrone: “Eu quis dar à senhora, Condessa, uma prova que a sua Fábula só pode viver aqui; mas a senhora quer continuar a leva-la em meio aos homens. Que seja!" (op. cit., p.107-108). O texto, que deveria ter uma conclusão no IV momento, termina com o barulho dos cavalos dos gigantes descendo a montanha:

O CONDE: (colocando-se à parte com a Condessa) Você não está com medo, Ilse? Está ouvindo?

SPIZZI: (aterrorizado, aproximando-se) As paredes estão tremendo!

CROMO: (aproximando-se aterrorizado também) Parece a cavalgada de uma horda selvagem!

DIAMANTE: Estou com medo! Estou com medo! (op. cit., p. 108-109).

Como observa o Eduardo: [...] essa questão da sobrevivência é difícil mesmo, é muito complicada. Temos atividades econômicas no teatro sempre caminhando no fio da navalha. Sorte em um determinado momento, quando estávamos atravessando um período difícil, que chamamos de tempos heroicos, o grupo teve a sorte de viajar para o exterior, travando contatos com grupos da América Latina (especialmente Peru, Colômbia, Europa e...) ligados a Teatro Antropológico, Eugenio Barba, Grotowski... Esses grupos tinham uma organização de trabalho muito conectadas às comunidades em que eles viviam. Eram grupos, [...] que estavam abandonando os grandes centros e buscando centros menores, buscando se desenvolver e constituir uma sede. Longe desses grandes centros, estes grupos se apresentavam, promoviam festivais de teatro para estas pequenas comunidades... Acho que, de certa maneira, este encontro com esses grupos nos ajudou a perceber a importância do teatro estar conectado com a comunidade em que ele vive e com as comunidades que ele encontra com mais frequência. Acho que nós artistas temos um desafio muito grande que é, também,

\footnotetext{
${ }^{3}$ Texto do próprio Pirandello que aqui em Os gigantes da montanha se passa como o texto do jovem poeta morto, apresentado de forma itinerante pela companhia de atores da Condessa.
}

${ }^{4}$ Cf Martha Ribeiro, Luigi Pirandello: um teatro para Martha Abba. São Paulo: Perspectiva, 2010. 
provar à comunidade que o teatro e a cultura são um valor em si para a comunidade. [...] É uma luta, as vazes achamos que caminhamos para frente, às vezes pensamos que estamos perdendo essa luta, mas vale a pena lutar.

E completa:

Eduardo: [...] o teatro de rua foi uma saída para o Galpão. Nós não éramos artistas conhecidos, a gente não tinha como ocupar as casas de espetáculo, então a nossa saída foi: "Queremos fazer teatro, vamos fazer teatro na rua, teatro de rua". [...] a rua economicamente foi importante pro Galpão, porque a gente ia pra rua, apresentava e as pessoas começaram a conhecer o trabalho do grupo. E, de repente, uma associação de bairro, um sindicato, uma prefeitura comprava um espetáculo por um cachê que era irrisório, mas que de certa maneira aquilo ali foi nos dando... Quer dizer, o caminho... não existe um caminho pronto, o caminho quem faz é o caminhante. A gente tem que encontrar o nosso caminho.

O teatro só existe se enfrentar os gigantes da montanha. Ainda que isso não signifique uma garantia para sua sobrevivência, deve ser feito. Pirandello sabia disso. Concluímos nossa reflexão com a certeza de que o final deixado incompleto, poucos segundos antes do abrir das cortinas e da entrada de llse no palco para enfrentar os gigantes, é muito significativo para entender o fazer teatral como um canto de experiência que nos faz tremer a carne toda noite, a cada apresentação. É um salto, sem paraquedas, no abismo. E como todo salto, não se tem nenhuma garantia no que vai dar... Pirandello também não sabia.

\section{Referências}

BENJAMIN, Walter. O Narrador. In: Magia e técnica, arte e política: ensaios sobre literatura e história da cultura. Obras escolhidas. V. 1. Editora Brasiliense: São Paulo, 1985.

LARROSA, Jorge. Tremores. Belo Horizonte: Autêntica Editora, 2014.

PIRANDELLO, Luigi. I giganti della Montagna. In: Maschere Nude, vol. IV, 2007.

PIRANDELLO, Luigi. Lettere a Marta Abba. Milano: Mondadori, 1995.

PIRANDELLO, Luigi. Os gigantes da montanha. Tradução Maria de Lourdes Rabetti. Rio de Janeiro: 7Letras, 2013.

RANCIÈRE, Jacques. A partilha do sensível. Tradução Mônica Costa Netto. São Paulo: Editora 34, 2009.

RIBEIRO, Martha. Luigi Pirandello: um teatro para Marta Abba. São Paulo: Perspectiva, 
2010.

RIBEIRO, Martha. Para um Teatro Performativo em Pirandello: um breve diálogo com Deleuze e o teatro da repetição. Revista brasileira de estudos da presença, v. 4, n. 3, p.527-550, 2014.

Recebido em: 03/02/2015

Aprovado em: 02/07/2015 